\title{
LA JUSTICIA CONSTITUCIONAL COMO LEGISLACIÓN: SCHMITT CONTRA KELSEN EN EL SIGLO XXI
}

\author{
Eduardo Hernando Nieto* \\ eehernan@ulima.edu.pe \\ Universidad de Lima, Lima, Perú \\ Recibido: 20/1/2021 Aprobado: 27/1/2021 \\ doi: https://doi.org/10.26439/iusetpraxis2021.n052.5067
}

\begin{abstract}
RESUMEN. Hoy en día no cabe duda del protagonismo de la interpretación constitucional en la práctica del derecho. Esto nos conduce a discutir el impacto que puede generar esta situación no solo en lo que podría significar la correcta administración de justicia, sino también en las enormes expectativas sobre el futuro de la democracia, que depende justamente de una adecuada aplicación del derecho. En el siglo pasado, el reconocido jurista alemán Carl Schmitt (1888-1985) consideraba que el desarrollo de la naciente justicia constitucional en Europa solo podría traer consigo una politización de la justicia y que el derecho no tendría nada que ganar con esto, sino, por el contrario, mucho que perder. Sin embargo, lo que en el siglo pasado era un tibio inicio se convirtió en una realidad dominante después de la Segunda Guerra Mundial. La justicia constitucional ha ido desplazando a la justicia ordinaria y, como consecuencia, se podría estar cumpliendo el vaticinio del profesor Schmitt. En este sentido, se buscará retomar los argumentos críticos de Schmitt frente a la tendencia de la constitucionalización del derecho, con énfasis en las debilidades de la llamada justicia constitucional y su fatal conversión en legislación.
\end{abstract}

PALABRAS CLAVE: justicia constitucional / politización de la justicia / interpretación constitucional / control de constitucionalidad / ponderación

\footnotetext{
* Doctor en Filosofía. Profesor de Filosofía del Derecho y de Lógica y Argumentación Jurídica en la Facultad de Derecho de la Universidad de Lima. Profesor ordinario del Departamento de Derecho de la Pontificia Universidad Católica del Perú. Profesor en las Facultades de Derecho de la Universidad de San Martín de Porres y la Universidad de Piura. Profesor en la Academia de la Magistratura.
} 


\title{
CONSTITUTIONAL JUSTICE AS LEGISLATION: SCHMITT AGAINST KELSEN IN THE 21ST CENTURY
}

\begin{abstract}
Nowadays, the prominent role of constitutional interpretation in the practice of law is an obvious fact. This leads us to discuss the impact of such situation not only in terms of a correct administration of justice but also as for the huge expectations about the future of democracy that depends exactly on the proper application of law. In the last century, a renowned German jurist, Carl Schmitt (1888-1985), considered that the emergence of constitutional justice in Europe could only lead to the politicization of justice and that the law would have nothing to gain from this but, on the contrary, much to lose. However, what in the last century was a lukewarm start turned into a dominant reality after World War II. Constitutional justice has been displacing ordinary justice and, as a result, the prediction of Professor Schmitt could be fulfilled. In this sense, Schmitt's critical arguments against this trend of constitutionalization of law will be taken up again, emphasizing the weaknesses of the so-called constitutional justice and its fatal conversion into legislation.
\end{abstract}

KEYWORDS: constitutional justice / politicization of justice / constitutional interpretation / constitutional control / weighting 
Los litigios constitucionales auténticos son siempre litigios políticos.

Carl Schmitt, Teoría de la Constitución (2011)

\section{¿QUÉ SIGNIFICA EL DERECHO Y QUÉ SIGNIFICA LA CONSTITUCIÓN? LOS ENFOQUES CONTRAPUESTOS}

En su conocido trabajo Teoría de la Constitución (2011), el profesor Carl Schmitt consideraba una serie de posibilidades para definir lo que es una Constitución, tanto en términos absolutos como en términos relativos. En cuanto a las del primer tipo, podía ser entendida como "la concreta situación de conjunto de la unidad política y ordenación social de cierto Estado" (p. 36); en pocas palabras, el Estado era la Constitución, lo cual implicaba afirmar que no podía haber normas que gobernasen la voluntad del Estado. Pero, en otro sentido - agregaba él一, también podía ser concebida como "una manera especial de ordenación política y social" (p. 37); esto es, la Constitución como forma de gobierno. Una tercera posibilidad era considerarla como el devenir dinámico de la unidad política (p. 38), pero igualmente era posible otra opción: comprenderla como "sistema de normas supremas y últimas" (p. 40). Justamente este último sentido era el que podría corresponder al rival intelectual del profesor Carl Schmitt, el jurista Hans Kelsen (18811973), para quien la Constitución no era sino un sistema normativo: "El derecho es un orden de la conducta humana. Un orden es un conjunto de normas que tienen el tipo de unidad a que nos referimos cuando hablamos de un sistema" (Kelsen, 2014, p. 3). De esta manera, finalmente, hablar del Estado sería hablar del sistema normativo y, a su vez, de la Constitución.

Ahora bien, era importante considerar que Schmitt (2011) definía también a la Constitución en términos relativos, en los que la dejaba de considerar como un todo y se centraba más bien en el concepto de ley constitucional: "Constitución, en sentido relativo, significa, pues, la ley constitucional en particular" (p. 45). De esta forma, resultaba esencial para Schmitt (2011) la distinción entre Constitución y ley constitucional, puesto que solo así se podría hablar realmente de Constitución:

No es admisible disolver primero la Constitución en una pluralidad de leyes constitucionales concretas y después determinar la ley constitucional por algunas características externas o acaso por el procedimiento de su reforma. De este modo se pierde el concepto esencial de la teoría del Estado y el concepto central de la teoría de la Constitución. (p. 57)

Entonces, cuando Schmitt (2011) hablaba de Constitución, se estaba refiriendo concretamente a un acto del poder constituyente que decidía la unidad política como algo existencial, por ello es que la Constitución tenía valor a medida que existía un poder. 
Así, mientras la Constitución tenía valor por obra de la voluntad política existencial, las leyes constitucionales existían gracias a la Constitución; en pocas palabras, la decisión prexistiría a la norma.

De allí que la esencia de la Constitución no pueda incluirse jamás en una regla o norma'. De esta manera y sintetizando las cosas, la Constitución para Schmitt sería el orden concreto que nace de la voluntad política, mientras que para Kelsen esta sería un sistema normativo.

\section{SOBRE LOS CONCEPTOS DE DERECHO Y POLÍTICA}

Para poder entender la naturaleza de la crítica schmittiana a la justicia constitucional, es necesario acudir también a su teoría legal, pues, a fin de cuentas, Schmitt fue fundamentalmente un jurista (Herrera, 2020).

En este sentido, como bien sostiene la profesora Montserrat Herrero, el profesor Schmitt, en un texto no tan conocido, Ley y juicio ${ }^{2}$, intentaba resolver una sola pregunta, que es sin duda medular, a saber: "¿Cómo encontrar un criterio interno a la praxis para saber cuándo podemos decir que una decisión judicial es correcta?" (Herrero, 2014, p. 27). El gran problema del derecho sería entonces el de la subsunción -como lo expondría Kant en su momento-, el poder fijar la forma como se puede relacionar una norma universal con un caso concreto, es decir, el problema de la relación entre la teoría y la práctica ${ }^{3}$.

La interpretación de la norma, así como también del hecho, evidencian a su vez la relevancia de la interpretación en la práctica del derecho. Sin embargo, Schmitt no plantea que solo a través de la subsunción es como se puede resolver la brecha entre lo universal y lo particular (Herrero, 2014), por lo que no podría ser válido afirmar que un razonamiento judicial es correcto cuando se subsume el caso en la norma. Precisamente, en el trabajo antes mencionado, se puede destacar la manera como en el contexto alemán ya la idea de la legalidad (subsunción) había sido superada por la Escuela Libre desde inicios del siglo xx, negándose la tesis de la ciencia jurídica que consideraba el derecho como una unidad lógica sin lagunas y que existía una correlación entre las fuentes y

1 Esto será central al momento de evaluar la crítica de Schmitt (2009) a la tesis de considerar a las Cortes o Tribunales Constitucionales como guardianes o defensores de la Constitución, pues, al final, los jueces serán a la ley como el soberano a la Constitución, por lo cual ningún tribunal podrá realizar esa tarea eminentemente política.

2 Se refiere a la obra Ley y juicio. Examen sobre el problema de la praxis judicial, de 1912, publicada en el libro Posiciones ante el derecho (Madrid: Tecnos, 2012).

3 Esto sería en el fondo lo esencial para Schmitt, quien identifica lo existencial como lo jurídico, por lo que el principal problema de la vida sería el de superar la tensión entre la regla general y el caso concreto. 
las decisiones (Schmitt, 2012). Schmitt discrepaba, entonces, de la idea de creer que se podría afirmar de manera objetiva la respuesta correcta.

La forma como el profesor Schmitt evalúa el tema de la legalidad y la subsunción resultará importante para poder entender la lógica de su cuestionamiento a la jurisdicción constitucional, y también para comprender mejor su concepción del derecho. Dice en este sentido: "Una decisión judicial es correcta si se puede esperar que otro juez hubiera decidido del mismo modo. Por otro juez se entiende aquí el tipo empírico de jurista moderno" (Schmitt, 2012, p. 99).

Así, para él, la legalidad no puede ser considerada como un criterio para poder establecer la validez del razonamiento jurídico, pues debe buscarse un criterio dentro del mismo derecho ${ }^{4}$, de lo que él llama la praxis. Sin embargo, el hecho de que no se tome en cuenta la legalidad no significa que todo quede en manos de la decisión subjetiva del juez (Schmitt, 2012). El concepto de praxis como lo usa él puede ser algo controvertido, ciertamente (Herrero, 2014). En principio, se podría referir a las decisiones en conjunto de los jueces, pero no se trata de precedentes en el sentido clásico, y más bien en último término podría ser concebido como una suerte de derecho consuetudinario (Herrero, 2014). De esta manera, un juez no debe resolver en función de un ideal de justicia, por ejemplo, o de componentes emotivos, sino sobre la base de la praxis actual, como se ha expresado (Schmitt, 2012). En otras palabras, Schmitt ubica la respuesta no en la norma, sino en el hecho.

Más adelante, en trabajos posteriores como Sobre los tres modos de pensar la ciencia jurídica (1996), Schmitt empleará el concepto de orden concreto para referirse al derecho, perfeccionando así el término de praxis. El orden concreto implica la reunión de la norma y la decisión dentro de un espacio y tiempo; se manifiesta, además, por medio de una serie de instituciones o corporaciones. Son ejemplos de órdenes concretos la Iglesia, la familia, la ciudad, etcétera. En este aspecto, estaría también influenciado por el llamado institucionalismo, propuesto por autores como Maurice Hauriou o Romano Santi (Croce y Goldoni, 2020). Así pues, el derecho, o bien se podría manifestar como una orden, o bien como una norma, pero siempre dentro del ámbito del orden concreto, lo cual implicaría afirmar que se actuaría dentro del marco jurídico, es decir, del ámbito corporativo.

La visión de corporación en Schmitt no podría desligarse de su famoso concepto de lo político, que se resumía en la esencia de la distinción entre amigos y enemigos (Schmitt, 2005). En otras palabras, para él, toda expresión de la vida humana se manifiesta en torno a la relación entre personas que comparten cosas en común y se distinguen de otros. De esta manera, quedaba clara su posición opuesta a cualquier perspectiva individualista o liberal, que proponía más bien la identificación de lo político y lo jurídico con

4 Lo que no significa que en muchos casos no pueda coincidir la legalidad con la corrección. 
lo individual, como ocurre, por ejemplo, con la identificación que hoy es muy usual entre el derecho y los derechos individuales.

El orden concreto implicaba siempre un colectivo que actuaba en el espacio y el tiempo, y que podría estar expuesto a los vaivenes de las circunstancias, pero destacándose esa intención o vocación de permanencia, del ser en el tiempo de la comunidad. Así, una decisión política o jurídica estaría, finalmente, conectada a la permanencia de ese orden concreto.

\section{EL PROBLEMA DE LA JUSTICIA CONSTITUCIONAL}

En La defensa de la Constitución (1988), Schmitt expresa su rechazo al sistema de control de constitucionalidad de las leyes ideado en la Constitución austriaca de 1920, bajo la guía del jurista socialdemócrata Hans Kelsen. Kelsen había sido encomendado en 1919 por el canciller socialdemócrata de la nueva República de Austria, Karl Renner, para elaborar el proyecto de Constitución y también para esbozar lo que sería una nueva instancia de control de los poderes entre el Estado Federal (Bund) y los Estados o Länder, como había existido antiguamente con el nombre de Tribunal Imperial (De Miguel y Tajadura, 2018). Inicialmente, la propuesta solo contemplaba la resolución de conflictos de competencia, la resolución de quejas contra el Bund o los Länder que no correspondían a la justicia ordinaria, entre otras; y únicamente se incluyó la posibilidad de que el gobierno federal pudiese impugnar alguna de las leyes de los Länder por un plazo definido ante el tribunal (De Miguel y Tajadura, 2018).

En las discusiones de la Asamblea Constituyente, se fueron haciendo diversos ajustes bajo la supervisión de Kelsen y se llegó a discurrir, finalmente, que deberían ser consideradas iguales las normas de los Länder y las del Estado Federal. Así se avanzaba en dirección a la creación de un órgano concentrado que pudiese enjuiciar cualquier norma, dejándose de lado la dimensión territorial - que le había dado nacimiento- para pasar a una tesis favorable a la unidad política y la Constitución. Nacía así el moderno control de constitucionalidad de las leyes.

La lógica de Carl Schmitt - alejada completamente del constitucionalismo liberal一, sin embargo, se mantenía dentro de la idea original, es decir, que la justicia constitucional tenía que ser exclusivamente política:

Un tribunal federal que falle sobre las cuestiones constitucionales suscitadas dentro de uno de los Estados federados es, al mismo tiempo, protector de la Constitución federal y de la del territorio respectivo. Particularmente es defensor de la homogeneidad constitucional que es inherente a toda Confederación. (Schmitt, 1998, p. 105) 
Entonces, cuando se planteaba un litigio de naturaleza constitucional, este tendría que ser de carácter político necesariamente. La dificultad se suscitaba cuando en la lógica de la justicia constitucional socialdemócrata (Kelsen) se pretendía enjuiciar una norma para poder determinar su constitucionalidad, pero la Constitución también iba a contener normas, por lo cual se planteaba el problema de subsumir una norma en otra, cuando la subsunción operaría siempre entre la norma y un hecho, como inteligentemente lo sostenía Schmitt (1998):

La aplicación de una norma a otra norma es algo cualitativamente distinto de la aplicación de una norma a un contenido real y la subsunción de una ley bajo otra ley (si es que acaso resulta imaginable) es algo esencialmente distinto de la subsunción del contenido concreto regulado. (p. 84)

En este sentido, si se trataba de una regla contra otra, entonces, lo que teníamos sería una antinomia que se arreglaría eliminando una de ellas, aunque en esta situación no se trataría de aplicar los criterios que son usuales en estos casos respecto a las reglas (Bobbio, 1999), porque sería una situación distinta, dada la jerarquía fijada entre la Constitución y las leyes. Pero lo más importante es que esto no podría ser calificado como un razonamiento judicial, porque, como se señaló, no habría aquí subsunción al tratarse de una norma constitucional frente a una norma legal. De esta forma, si la propia Constitución señalase la prohibición de elaborar normas que puedan contradecir lo que esta estableciera, ¿qué pasaría en el caso de que alguien pudiese crear una norma que contradijese la Constitución? Lo primero que podría sostenerse, siguiendo a Schmitt (1998), es que esta prohibición no podría ser considerada justicia constitucional, sino una “justicia penal represiva” (p. 86) y, en esta situación, el problema no estaría en la norma, sino en quien la creó cometiendo este ilícito; es decir, "la única justicia que resulta posible en un caso semejante es la justicia penal vindicativa contra el autor de preceptos constitucionales, pero no contra una norma" (Schmitt, 1998, p. 87). Kelsen (1995), en respuesta a esta crítica contundente de Schmitt, solo se remitió a señalar que este último estaba equivocado, porque no se trataría de confrontar una norma contra otra, sino de una ley como norma y otra ley como un hecho concreto.

La rápida evolución de la justicia constitucional después de la Segunda Guerra Mundial, particularmente en la Alemania Federal, parece haberle dado la razón al profesor Schmitt no solo respecto al gran protagonismo de esta, sino también a su actuar político, aunque revestido con un ropaje jurídico. El auge de la doctrina de los derechos fundamentales, es decir, de los principios y valores del liberalismo moderno, que han llegado a convertirse en la parte sustantiva de la Constitución actual, ha llevado a que todo acto político quede sometido a la autoridad de la Constitución y los derechos, como bien lo acota un conocido exponente del constitucionalismo contemporáneo:

El papel de los derechos fundamentales en el sistema jurídico cambiaría de modo radical. Los clásicos derechos fundamentales reducían su alcance a una parte del 
sistema jurídico: la relación entre el Estado y el ciudadano; en cambio, los derechos fundamentales, entendidos como principios, desplegarían sus efectos a lo largo de todo el ordenamiento jurídico. De este modo, generarían una eficacia expansiva a todos los ámbitos jurídicos, que conduciría necesariamente a una eficacia horizontal o eficacia frente a terceros de los derechos fundamentales; así como al reconocimiento de que existen contenidos iusfundamentales de protección, de aseguramiento social y de organización y procedimiento, que exigen una actuación positiva del Estado y que no se limitan — como los clásicos derechos de libertad-a exigir únicamente omisiones estatales. Los derechos fundamentales se convertirían por esta vía en los "principios de mayor jerarquía del ordenamiento jurídico en su conjunto". Como tales, en definitiva, ya lo contendrán todo. Solo sería necesario concretarlos por medio de la ponderación. (Alexy, 2002, pp. 15-16)

La ponderación y la proporcionalidad que reclama el profesor Robert Alexy (2002) como vía para interpretar la Constitución en casos concretos es, sin embargo, una práctica que no nace en la propia justicia constitucional, sino en el derecho administrativo alemán, en el Tribunal Supremo Administrativo Superior de Prusia, específicamente en el derecho policial, y respecto a los casos en los cuales este tribunal había establecido que la policía debía emplear la fuerza de una manera contenida y responsable (Forsthoff, 2013).

El desarrollo de la justicia constitucional después de la Segunda Guerra Mundial surge, pues, de la práctica del derecho administrativo, en donde claramente se manifiesta, por un lado, la tensión entre el poder estatal y los derechos ciudadanos; y, por otro, la innegable presencia de la discrecionalidad como resultado de la generalidad de las normas y la peculiaridad y variedad de los casos. Todo esto lleva, entonces, a que esta justicia constitucional exprese un significado político ya desde su propio nacimiento.

Pero, si seguimos lo dicho también por Alexy (2002), el constitucionalismo contemporáneo lo penetraría todo en la medida que todo derivaría de los derechos fundamentales, aun la propia legislación. En este sentido, siempre resultaría pertinente la conocida alusión del constitucionalista alemán Ernst Forsthoff (1902-1974) al denominado huevo jurídico para referirse precisamente a esta forma de constitucionalismo:

La discrecionalidad es una cuestión propia de la ejecución de la ley. A través de la discrecionalidad del legislador, la legislación se convierte en ejecución de la Constitución. Ahora bien, es muy diferente que se piense que el legislador está vinculado a la Constitución, o que se entienda que el legislador haya de limitarse a ejecutarla; una opinión, por lo demás, para cuyo rechazo basta una mirada a la Constitución. No por ello está menos extendida en alguna medida la idea de que las leyes, como, por ejemplo, el Código Procesal Penal, son el desarrollo más inmediato y, por ello, la ejecución de lo que en la Constitución está preformado y dispuesto. La Constitución sería así un huevo de Colón jurídico [cursivas añadidas], del que todo surge, desde el Código Penal hasta la ley sobre la fabricación de termómetros. (Forsthoff, 2013, p. 107) 
El tema es, sin embargo, que en el derecho administrativo la discrecionalidad está limitada generalmente por la misma ley; en cambio, la Constitución no presenta estos límites y más bien ella pretende fijar los límites a la discrecionalidad del legislador (Forsthoff, 2013).

Siguiendo el análisis del profesor Forsthoff - totalmente convergente con las tesis de Schmitt-, el plantear esta interpretación de la Constitución, como si ella englobase toda la existencia de la colectividad, y ordenar, por consiguiente, la ejecución de sus mandatos a todas las autoridades, incluyendo a los legisladores, no sería otra cosa que una expresión de la ideología liberal o socialdemócrata (Vázquez, 2012) que subyace a esta manera de interpretación, conocida hoy también como el concepto de neoconstitucionalismo ${ }^{5}$.

Finalmente, el empleo de estos conceptos administrativos en el constitucionalismo de hoy se muestra claramente cuando se busca llenar lagunas en la Constitución:

La aplicación de conceptos administrativos en la legislación como una función del derecho constitucional es notoria en varios aspectos. Sirve, como ya indicamos, para satisfacer una necesidad evidente, en la medida en que cubre una laguna en la Constitución. La Constitución del Estado de derecho no dice nada acerca de las prestaciones estatales, especialmente las propias del Estado social; y esto no precisamente por olvido o indolencia, sino por razones de su estructura lógica, ya que no puede contener criterios válidos en relación con medidas como esas prestaciones, que no resultan compatibles con la certidumbre de la libertad en el marco de la ley, la única exigencia que la Constitución ha de garantizar. Esta laguna se ha venido cubriendo mediante la nueva interpretación del principio de igualdad como prohibición de arbitrariedad del legislador, mediante la elevación del principio de proporcionalidad a la categoría de norma constitucional no escrita y mediante la elevación del concepto de discrecionalidad legislativa. (Forsthoff, 2013, p. 109)

La tesis de Forsthoff, junto con las señaladas por Schmitt, apuntan sin dudar a la clara interferencia de la justicia constitucional en la dinámica política, dejando de actuar esta, como decía Kelsen (1994), como un legislador negativo y convirtiéndose más bien en un activo legislador que, con la lógica de "desarrollar la Constitución", estaría interviniendo abiertamente en el gobierno, pasando por alto la propia estructura clásica del Estado constitucional y la separación de poderes, así como también la legitimidad democrática que es un componente relevante de la propia Constitución. Si bien es cierto que Kelsen reflejaba un concepto descriptivo de Constitución como norma y el constitucionalismo actual de autores como Alexy o Dworkin el modelo axiológico de Constitución

5 Esto es justamente lo que se ha acuñado como neoconstitucionalismo o teoría constitucional contemporánea, es decir, el enfoque interpretativo que prioriza el desarrollo de la Constitución a favor del principio de igualdad (Pozzolo, 2011). 
como norma (Comanducci, 2007), es decir, una forma más clara de justicia constitucional iusmoralista, ambos enfoques se confrontan con los fundamentos de las tesis de Schmitt y Forsthoff respecto al carácter político de la justicia constitucional.

\section{ALGUNAS CONCLUSIONES}

La justicia constitucional socialdemócrata — para distinguirla de la revisión judicial norteamericana-, que ha nacido en el contexto de Europa continental y que ha influido en muchos lugares del mundo, sobre todo después de la Segunda Guerra Mundial, ha establecido una nueva forma de gobierno, una suerte de gobierno de la Constitución, pero por medio de los jueces y, particularmente, por los jueces constitucionales.

Sin embargo, como hemos visto a lo largo del texto, esta justicia constitucional no expresa estrictamente hablando un razonamiento judicial, porque el razonamiento judicial es subsuntivo, cosa que no aparece en la interpretación constitucional. Como sostuvieron Schmitt y luego Forsthoff, la justicia constitucional hunde sus raíces en el derecho administrativo (público), por lo cual es innegable su vínculo con lo político. En sus orígenes, esto se manifestó en el rol que jugaban los tribunales al momento de dirimir competencias entre el gobierno federal y los estados miembros, es decir, dirimir entre poderes. Hoy la justicia constitucional asume la idea de ser una última instancia de administración de justicia y de tutela de los derechos fundamentales, pero al hacer esto viene suplantando a la rama legislativa, pues la jurisprudencia que impone se vuelve en mandatos para todas las autoridades. El problema, finalmente, sería el hecho de fungir de jueces, pero decidir como legisladores, con todos los inconvenientes que esto pueda traer para la vida social, como la falta del pluralismo que sí puede encontrarse en un parlamento o la legitimidad democrática de la que también suele carecer esta forma de justicia. Una verdadera defensa de la Constitución debería proteger, entonces, la existencia de la comunidad y no los derechos individuales, como concluiría, finalmente, Schmitt.

\section{REFERENCIAS}

Alexy, R. (2002). Epílogo a la Teoría de los derechos fundamentales. Revista Española de Derecho Constitucional, 22(66), 13-64.

Bobbio, N. (1999). Teoría general del derecho. Madrid: Debate.

Comanducci, P. (2007). Modelos e interpretación de la Constitución. En M. Carbonell Sánchez (Coord.), Teoría del constitucionalismo: ensayos escogidos (pp. 41-70). Madrid: Trotta. 
Croce, M., y Goldoni, M. (2020). The legacy of pluralism. The continental jurisprudence of Santi Romano, Carl Schmitt and Constantino Mortati. Stanford, CA: Stanford University Press.

De Miguel, J., y Tajadura, J. (2018). Kelsen versus Schmitt. Política y derecho en la crisis del constitucionalismo. Madrid: Escolar y Mayo.

Forsthoff, E. (2013). El Estado de la sociedad industrial. Madrid: Fundación Coloquio Europeo; Centro de Estudios Políticos y Constitucionales.

Herrera, H. (2020). Carl Schmitt between technological rationality and theology. Nueva York: SUNY Press.

Herrero, M. (2014). La respuesta de Carl Schmitt al problema de la decisión judicial. En J. Peña González (Coord.), Carl Schmitt y el decisionismo jurídico (pp. 27-39). Madrid: Fundación Universitaria San Pablo CEU.

Kelsen, H. (1994). La garantía jurisdiccional de la Constitución. La justicia constitucional. lus et Veritas, 5(9), 17-43.

Kelsen, H. (1995). ¿Quién debe ser el defensor de la Constitución? Madrid: Tecnos.

Kelsen, H. (2014). Teoría general del derecho y del Estado. Ciudad de México: Universidad Nacional Autónoma de México.

Peña González, J. (Coord.). (2019). Carl Schmitt y el decisionismo jurídico. Madrid: Fundación Universitaria San Pablo CEU.

Pozzolo, S. (2011). Neoconstitucionalismo y positivismo jurídico. Lima: Palestra Editores.

Schmitt, C. (1996). Sobre los tres modos de pensar la ciencia jurídica. Madrid: Tecnos.

Schmitt, C. (1998). La defensa de la Constitución. Madrid: Tecnos.

Schmitt, C. (2005). El concepto de lo político. Madrid: Alianza.

Schmitt, C. (2011). Teoría de la Constitución. Madrid: Alianza.

Schmitt, C. (2012). Posiciones ante el derecho. Madrid: Tecnos.

Schmitt, C., y Kelsen, H. (2018). La polémica Schmitt/Kelsen sobre la justicia constitucional: El defensor de la Constitución versus ¿Quién debe ser el defensor de la Constitución? Madrid: Tecnos.

Vázquez, R. (2012). Consenso socialdemócrata y constitucionalismo. Ciudad de México: ITAM; Fontamara. 
